\title{
An Analysis of Japanese Sentence-final Particle Yone: Compare Yone and $\mathrm{Ne}$ in Response
}

\author{
Jun Xu \\ Colorado State University, \\ Fort Collins, USA \\ JUN.XU@COLOSTATE.EDU
}

Editor: Kallirroi Georgila

Submitted 01/2020; Accepted 10/2021; Published online 12/2021

\begin{abstract}
Yone, a Japanese sentence-final particle (SFP), is frequently used in conversation, and some functions overlap with $n e$, another SFP. However, not much discussion has taken place about their differences. This study argues that the two Japanese sentence-final particles, yone and ne, express a distinction about the speaker's state of mind: yone indicates that an idea has been on the speaker's mind, while ne suggests a thought just emerged into the speaker's awareness. Naturally occurring conversation data provides evidence for this claim. The results show that the particles reflect the speaker's choice of presenting his/her state of awareness.
\end{abstract}

Keywords: Japanese, discourse, pragmatics, sentence-final particle, yone

\section{Introduction}

$\mathrm{Ne}$ and yone are two frequently used Japanese sentence-final particles in conversation (e.g., AsanoCavanagh, 2011; Cook, 1990, 1992; Hasegawa, 2010; Hasunuma, 1992, 1995; Hayano, 2011, 2013; Izuhara, 1993, 1994, 2001, 2003, 2008; Kamio, 1994, 1995, 1997; Katagiri, 2007; Kato, 2001; Lee, 2007; Maynard, 1993; Miyazaki 2002; Morita, 2002; Saigo, 2011; Takubo \& Kinsui, 1997; Tanaka, 2000; Xu, 2016; Zhang, 2009). While both yone and ne can be used as tag-like questions to seek confirmation, they can also show agreement or empathy (e.g., Hasunuma, 1992, 1995; Izuhara, 1993, 1994, 2001, 2003; Noda, 1993). Although yone and ne functions overlap, interchangeability has not been thoroughly studied (Asano-Cavanagh, 2011; Hayano, 2013; Noda, 1993; Xu, 2016). Also, as Hayano (2011) points out, research on Japanese sentence-final particles tends to consider that their use is rule-governed by the objectively discernible distribution of knowledge or information. However, such perspective overlooks the agency of the individual in presenting knowledge of information when using sentence-final particles through the dynamic courses of conversation (Hayano, 2011).

Using naturally occurring conversation data where yone and ne occur in a response environment, the present study attempts to show these differences between yone and ne:

a. Yone is a marker of existing awareness that indicates an idea had already been on the speaker's mind.

b. Ne is a marker of new awareness that shows a thought just emerged into the speaker's awareness.

c. What ne presents is not necessarily something new, and it can be something the speaker had not thought of until the time of utterance.

d. Speakers systematically select yone or ne to present their states of awareness.

It is necessary here to clarify three critical terms in this study: "response," "new awareness," and "existing awareness." First, according to the Merriam-Webster dictionary, a response is 
something constituting a reply or a reaction. ${ }^{1}$ In other literature, a response can appear as the answer part in a summons-answer sequence (Schegloff, 2007), an initial assessment of something, or the second assessment in an assessment pair (Pomerantz, 1984). In this paper, the term "response" is used in a broad sense to examine four situations: (i) response to immediate conditions; (ii) response in recall; (iii) response to the answer to a question; and (iv) response to assessment. ${ }^{2}$

Second, throughout this paper, the term "new awareness" is used to describe what a speaker currently thinks, feels, or what the speaker has just noticed or recalled at the time of the utterance. Third, "existing awareness" refers to the speaker's knowledge or thoughts, such as information mentioned in previous discourse or knowledge already established before the moment of utterance.

Worth noting is that the present study does not intend to provide a general account for the distinction between yone and ne. Instead, this examination is limited to only four situations in response. However, they reveal how a speaker systematically displays one's state of awareness with ne and yone.

This article follows this organizational structure: The first section deals with the background of this study. The second part concerns the data and methodology of this study. Data analysis constitutes the third part, and the fourth part concludes this study.

\section{Background}

This section provides a brief review of the overlapped functions of yone and ne, the differences between them in response as showing agreement, and the relationship between information status and the choice of linguistic forms in Japanese.

\subsection{The Differences Between Yone and $\mathrm{Ne}$ in Response}

The literature has identified that yone has a few overlapped functions with ne (e.g., AsanoCavanagh, 2011; Hasunuma, 1992, 1995; McGloin et al., 2013; Miyazaki, 2002; Noda, 1993; Zhang, 2009). This study focuses on ne and yone as response, which appears as agreement in Examples (1) and (2). ${ }^{3}$ Here, responding to the assessment in line 1, speaker B can use either $n e$ or yone in line 2 to show the agreement with speaker A's opinion, i.e., this restaurant's sushi is delicious.

(1)

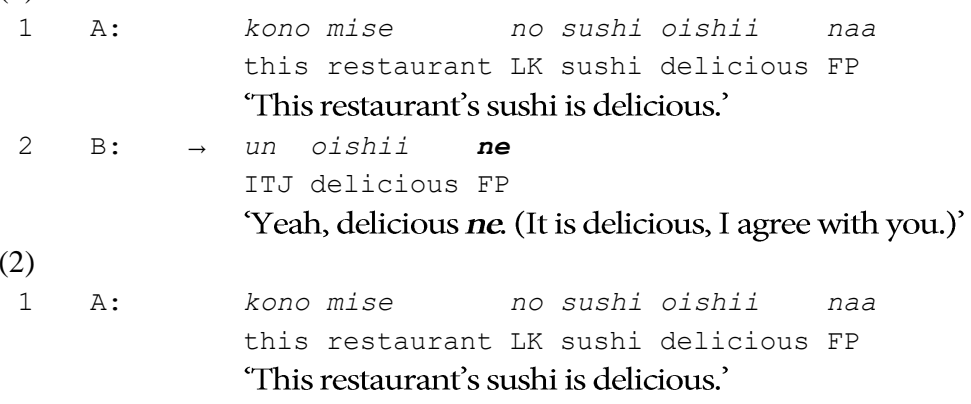

\footnotetext{
${ }^{1}$ Response [Def. 2]. (n.d.). In Merriam Webster Online, Retrieved April 18, 2021, from http://www.merriamwebster.com/dictionary/response.

${ }^{2}$ Assessment is an action or an instant judgment about something. It is an interactive action commonly examined in Conversation Analysis (Pomerantz, 1984). She points out that "assessments are produced as products of participation; with an assessment, a speaker claims knowledge that which he or she is assessing" (Pomerantz, 1984:57). In the present study, ne-marked or yone-marked responses commonly appear as assessments. However, a response does not always appear as an assessment. Assessment is one category of response in this article.
}

${ }^{3}$ See Appendix for the list of abbreviations and transcription conventions. 


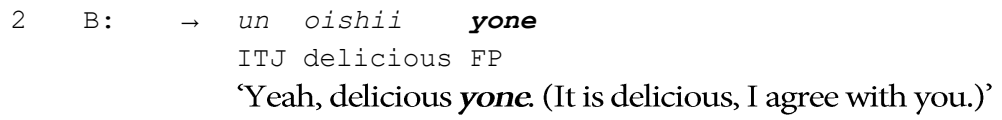

To date, the differences between using yone and $n e$ in Examples (1) and (2) have received scant attention in the literature. Only Noda (1993) has discussed this issue by pointing out that yone and $n e$ are not always interchangeable. She argues that in certain situations, one rather than the other is natural. For instance, ne is acceptable in Example (3) while yone cannot be used at the same turn in Example (4). Noda (1993:14) argues that yone cannot be used in greetings, so (4)B is incorrect.

(3)

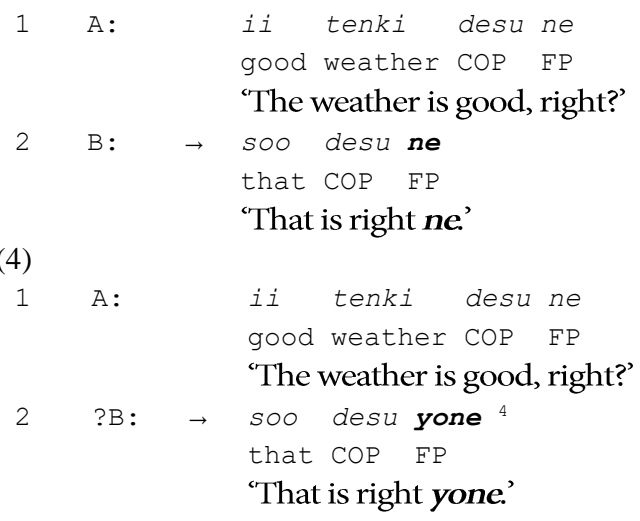

However, Noda's (1993) proposal fails to explain why yone and ne are not interchangeable in Example (5) even though they are in a non-greeting situation. In Example (5), the participants are talking about hourly pay at their part-time jobs. After finding out speaker B's hourly pay rate, speaker A comments that the pay rate is low (line 1). Speaker B shows his agreement with speaker A in line 2. In line 3, when speaker A further displays his response that the pay is low, only yone is possible. If $n e$ is used in the same position (Example 5, line 3), the whole utterance becomes unnatural.

(5)

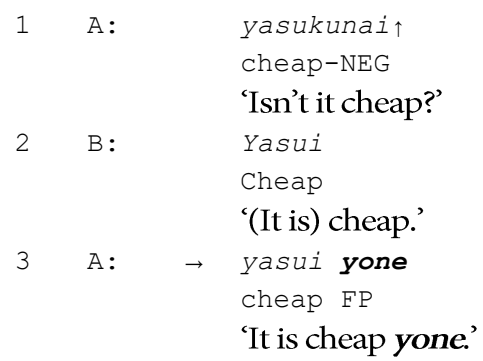

Surprisingly, no studies have discussed yone and ne as used in Example (5). Because Noda's (1993) proposal cannot successfully explain the use of yone in Example (5), this study attempts to show the difference between yone and ne through a new approach.

\footnotetext{
${ }^{4}$ This sentence was judged as incorrect with a "*” mark by Noda (1993), but it is replaced with "?" in this study. Five Japanese native speakers were consulted about the naturalness of this example. One reported that the sentence 4(B) is unnatural. While the other four considered it acceptable, all agreed that the sentence 3(B) is more natural. What is important when changing the "*" mark to the "?" mark for 4(B), however, is that 3(B) is more appropriate than 4(B) in terms of naturalness even though native speakers might have different opinions about accepting sentence $4(B)$.
} 


\subsection{Information Status and the Choice of Linguistic Forms in Japanese}

In many languages, speakers choose different linguistic features to present the various statuses of information (e.g., Akatsuka, 1985; Goldsmith \& Woisetschlaeger, 1982; Gundel, 1985; Kamio, 1997; Kuno, 1972; Miyazaki 2002; Prince, 1992; Slobin \& Aksu, 1982).

For instance, in Japanese, Kuno (1972) uses the notion of "old/new information" to explain the use of two particles, $w a$ and $g a$. He proposes four different usages of $w a$ and ga: thematic $w a$, contrastive $w a$, descriptive $g a$, and exhaustive-listing $g a$. He further points out that thematic $w a$ presents old information while descriptive $g a$ and exhaustive-listing ga convey new information.

Akatsuka (1985) illustrates the vital role a speaker's awareness plays in the choice of forms for conditionals. She argues that an understanding of what registers the speaker's awareness at the time of the utterance is pivotal in distinguishing the conditional $S_{1}$ no nara $S_{2}$ from other conditionals in Japanese. When $S_{1}$ no nara $S_{2}$ appears, $S_{1}$ always expresses new information that has just entered the speaker's awareness at the discourse site. She also notes that Japanese grammar is sensitive to the cognitive distinction between "newly-learned information" and the "state of knowledge."

Kamio (1997) distinguishes the Japanese sentence-final particles yo and ne using the theory of "territory of information," a theory based on the notion of psychological distance between a given piece of information and the speaker/hearer (see Kamio 1994, 1995, 1997 for details of the territory of information theory). He claims that the particle ne is a marker of shared information, which indicates a piece of information presumably within both the speaker's and addressee's territories. In contrast, the particle yo implies that the speaker and addressees do not share a piece of information. Such information exists in the speaker's territory but not within the addressee's territory.

Using the term “認識の現場性 ninshiki no genbasei (immediate awareness),” Miyazaki (2002) argues that $n e$ as well as its corresponding particle in monologue, na/naa, present that a speaker's awareness is what he/she thinks, feels, and notices at the time of utterance. He used examples of ne and $n a$ from novels to argue this point (Miyazaki, 2002:11). For instance, ne and naa in Examples (6) and (7) are used to present the speaker's thoughts about what he/she has just seen.

(6)

[Shoya looked at Nobuko, who is in front of him.]

odoroita ne!-marude betsujin da yo.

'I am so surprised ne. You look like someone else.'

(7)

"Nobuko san?"

to me o mihatta.

"Odoroita naa!-marude betsujin da yo."

"Nobuko?"

(He) opened his eyes widely.

"I am so surprised naa! You look like someone else."

All the studies reviewed here suggest it is possible to analyze the difference between yone and $n e$ from a new perspective by focusing on how speakers use yone and ne to represent their states of awareness. The present study follows Miyazaki's (2002) framework of $n e$, which shows the importance of a speaker's awareness and analyzes the use of yone and ne in four responding situations. As described in the Introduction section, the present study argues that the differences between yone and ne are:

a. Yone is a marker of existing awareness that indicates that an idea had already been on the speaker's mind.

b. Ne is a marker of new awareness that shows a thought just emerged into the speaker's awareness. 
c. What ne presents is not necessarily something novel, and it can be something the speaker had not thought of until the time of utterance.

d. Speakers systematically select yone or ne to present their states of awareness.

\section{Data and Method}

The present study examines the use of yone and ne in conversation using a cognitive-interactive framework. The reasons for this particular approach are twofold: First, this study's argument about the use of yone stems from Miyazaki's (2002) proposal about ne, which focuses on the speaker's awareness. Second, unlike the data used in Miyazaki (2002) and Noda (1993), which were constructed or taken from novels, this study examines how yone and ne are used in social interaction.

Methodologically, the present study proposes hypotheses about using yone and ne based on constructed, written, and conversation data. Naturally occurring conversation data provided the data for testing the hypotheses. To carefully examine the conversation data, conversation analysis (CA) with modification was partially adopted.

The data consists of nine sets of face-to-face video-recorded multi-party conversations. The source of the data is the Sakura Corpus distributed by the TalkBank organization. ${ }^{5}$ Conversation participants are native speakers of Japanese who are students at a Japanese university. In each video session, four students, who are classmates or close friends, talk about a given topic. Because the conversation participants were close, they used the non-polite conversation style ( $d a$-form). While the Sakura Corpus has 18 sets of conversation data, the data included in this study are female-male conversations and all-female conversations. Other data with fewer cases of yone, such as all-male conversations, were excluded. Although the data bias is toward female participants, gender is not a contributing factor to the general conclusion of the present study. Also, while two male participants' utterances were occasionally affected by dialect, the corresponding sentence-final particle yone in the dialect, yona, was not identified in the data. Thus, dialect does not influence the use of yone in this study's data.

There are 397 cases of yone in the final data examined for this study. Of those, 86 instances were speaker responses to various situations and, therefore, constitute this study's focus. Meanwhile, there are 1230 cases of $n e$ in the same data sets since $n e$ is the most frequently used sentence-final particle in Japanese conversation (Hasegawa, 2010).

The study first examined the 86 cases of yone for responses and identified four responding situations. Then, another 53 cases of $n e$ in the same responding situations were compared with the cases of yone in response. This study did not identify and categorize all the instances of $n e$ in response; this study's primary focus is yone while ne is used to compare with yone.

Data was transcribed using the revised Hepburn system of Romanization. Although transcription of utterances used standard Japanese pronunciations, paralinguistic features, such as pauses, sound stretches, and overlapping speech, were also noted in the transcription according to the transcription conventions developed by Jefferson (1984) with modifications. Also noted were non-vocal actions such as gestures, body alignment, and other contextual information. Roman letter codes masked individual speakers, providing anonymity.

\footnotetext{
${ }^{5}$ The data are from the database of TalkBank (https://sla.talkbank.org/TBB/ca/Sakura). Most transcriptions of examples in this paper were updated to include details such as overlapped utterances, pauses, and gestures. Such non-verbal communication can provide critical supplemental cues when evaluating a speaker's intention and such inclusion adds to the argument of the present paper. In addition, five Japanese native speakers were consulted to ensure the accuracy of the final transcriptions used in the present paper.
} 


\section{Result and Discussion}

In this section, yone and ne as used in four response situations will be carefully examined and discussed.

\subsection{Response to Immediate Situations}

In this study, "immediate situations" refers to situations in which the speaker has just received new information by seeing or hearing at the time of conversation. What the speaker has just seen or heard triggers a $n e$-marked utterance. In the present study data, ne is commonly used in such situations while yone is not.

Example (8) illustrates the use of ne based on what the speakers have just seen and heard. Four participants are talking about their ideal partners. Before the segment, speaker $\mathrm{H}$ says that he likes girls wearing framed glasses. Speakers L and K, two females, wonder what makes glasses appealing to speaker $\mathrm{H}$.

(8)

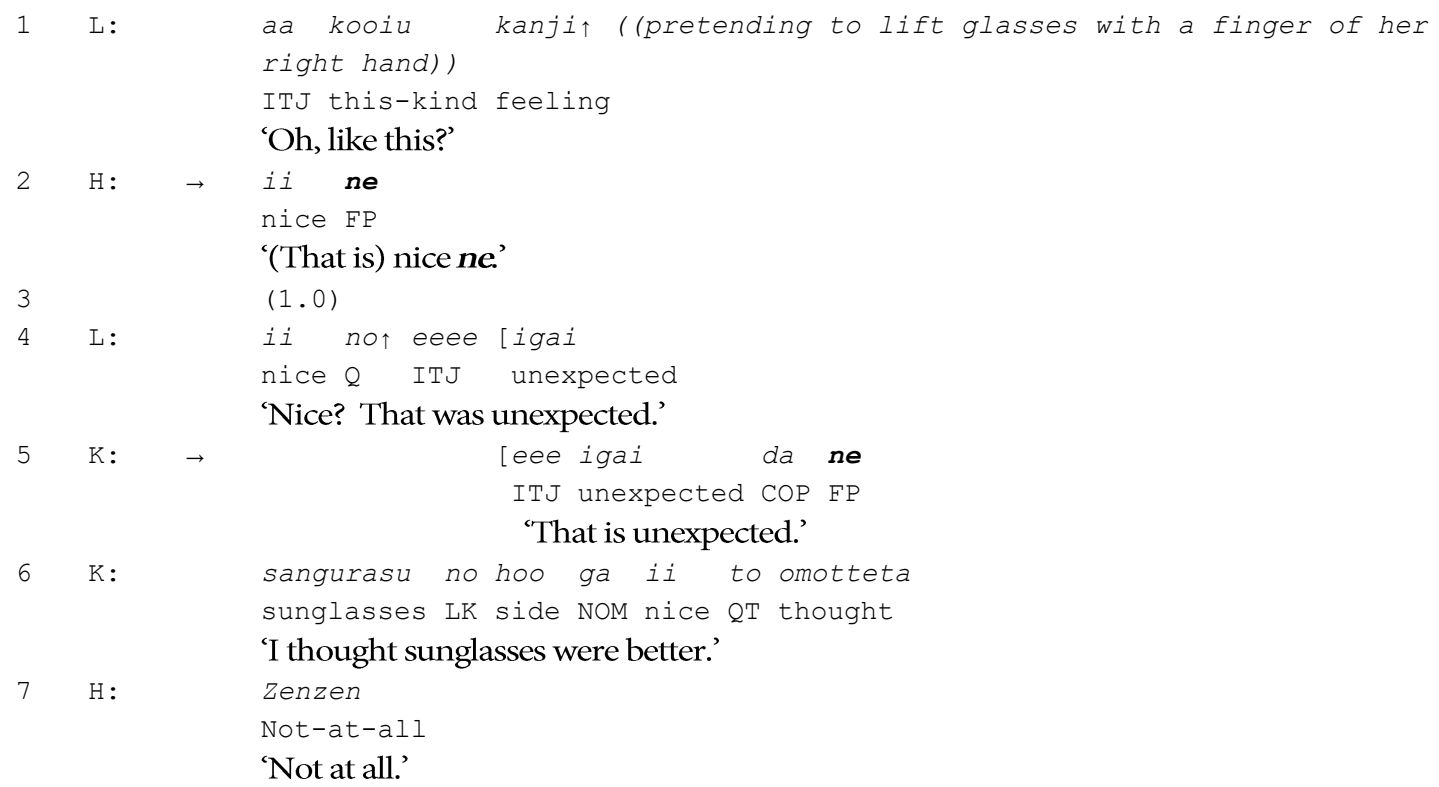

In line 1, speaker L uses gestures like touching the frame of a pair of glasses. Speaker $\mathrm{H}$ responds to the action with a $n e$-marked comment (line 2). His response "ii $n e$ (that is nice)" is based on the immediate observation of speaker L's action. Thus, here speaker H uses ne to reflect what he has just observed. Another speaker, K, produced a ne-marked comment in line 5. Her immediate comment, "igai da ne (that is unexpected)," is based on what she has just heard from speaker H's response in line 2. Her thought that sunglasses were better was different from what she heard from speaker H's response. This difference indicates that newly-learned information triggered the use of $n e$.

Example (8) shows that $n e$ is triggered by what the speaker has just seen or heard. This finding is consistent with Miyazaki's (2002) proposal. On the other hand, no yone-marked response exists in such situations in this study's data.

\subsection{Response in Recall}

In 4.1, we saw that only ne exists in response to what the speaker has just seen or heard. However, both $n e$ and yone can be used in response where the speaker has just been reminded of alreadyknown information. This section will illustrate how ne and yone are used to respond to the speaker's already-known information in recall. In this study, "recall" refers to situations in which old 
information, such as information mentioned in previous discourse or knowledge already established before the moment of utterance, was brought into the speaker's mind.

\subsubsection{Ne in Recall}

Example (9) shows how ne relates to the speaker's own experience, which is already-known information to the speaker. Four participants talk about their ideal partners in this segment. Speakers H and G, two male participants, previously spoke about the same topic with others in a different session. Two female participants, $\mathrm{L}$ and $\mathrm{K}$, ask them what they talked about in the previous session. After being reminded of some of their discussion topics, they are asked about another issue (line 1). Now speaker $G$ has trouble recalling their conversation topics.

(9)

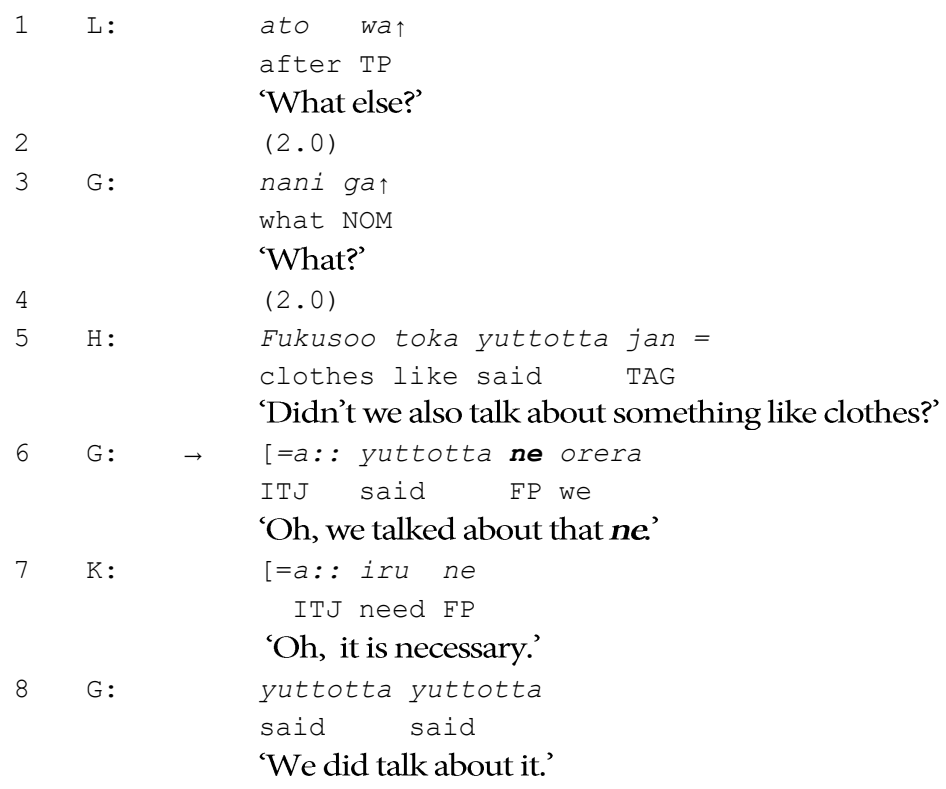

Speaker H's utterance in line 5 triggers speaker G's ne-marked response in line 6. Although the information regarding what else they talked about as criteria for ideal partners in a different session is not new to speaker $\mathrm{G}$, the information was not in his awareness until triggered by speaker H's comment that they also talked about clothes in line 5. Speaker G's ne-marked response produced in line 6 indicates that the information just entered speaker G's awareness. Furthermore, the ne-marked response associates with the change-of-state marker " $a::$. " (line 2) (Heritage, 1984). Thus, here ne can be considered as displaying new awareness.

\subsubsection{Yone in Recall}

Example (10) illustrates the use of yone where the speaker talks about information already-known to him/her.

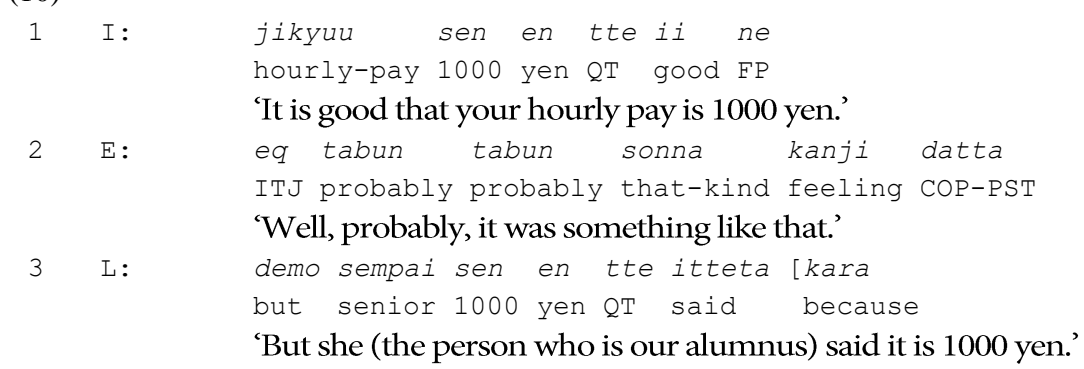




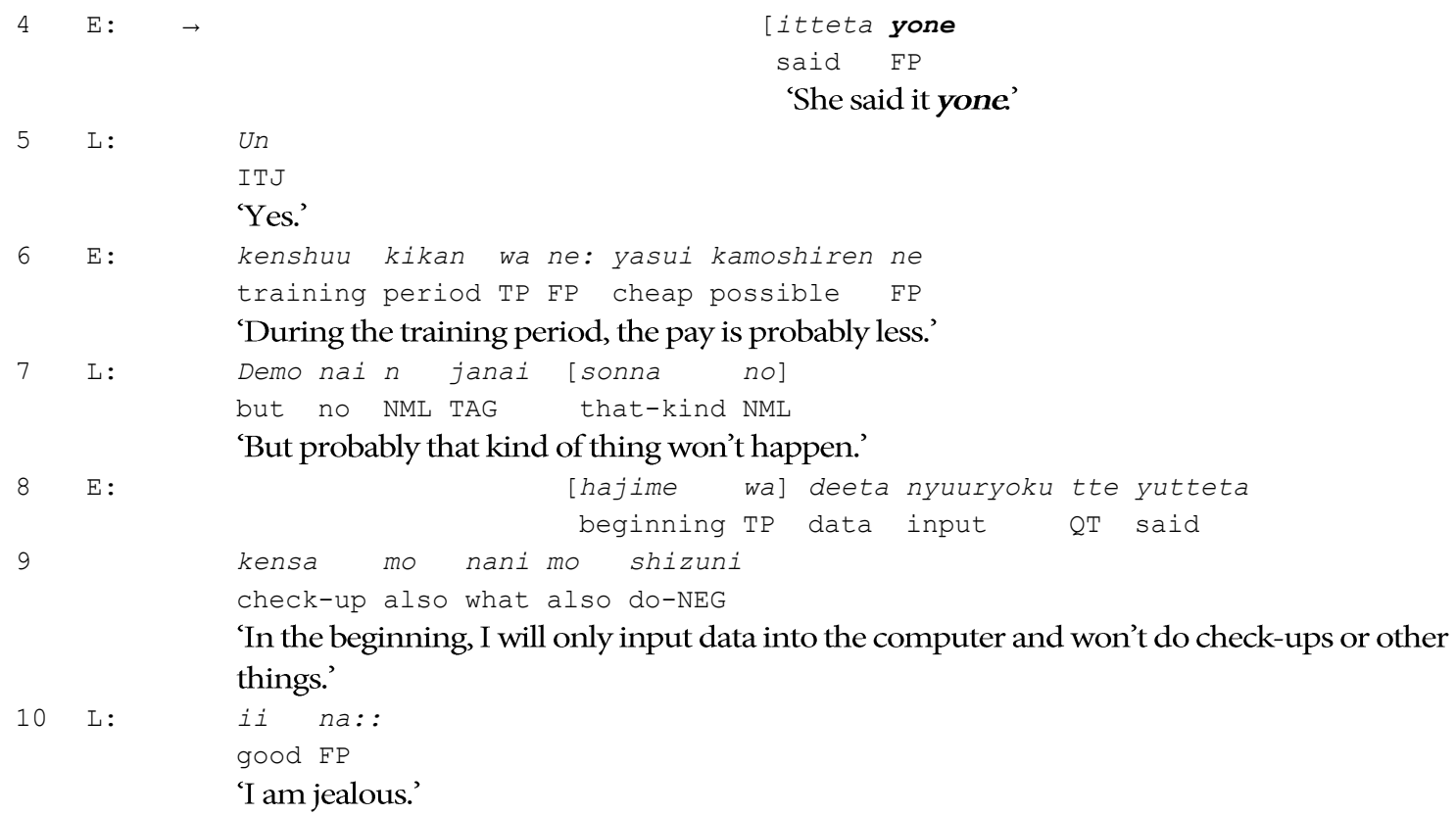

Before this segment, speaker E told others that she ran into an alumnus at a clinic where the alumnus works. Speaker E had an opportunity to work there, and the hourly pay was 1000 yen. Maybe because she has not started to work there yet, and her job will be only inputting data into a computer without doing anything such as checking patients (lines 8 and 9), she downgrades her stance (line 2). She does this by showing uncertainty with the adverb "tabun (probably)" when speaker I comments on how good the pay is (line 1). In line 3, speaker L mentions that the alumnus has said the pay is 1000 yen, and speaker E produces the yone-marked response in line 4. Indeed, she knows what the alumnus said about the hourly wage, and the information about hourly pay was already-known information to her. Her immediate yone-marked response shows that she knows the information clearly and has no problem in recall (line 4).

\subsubsection{The Differences Between $\mathrm{Ne}$ and Yone in Recall}

The environments are distinctly different when comparing the yone-marked response in Example (10) with the $n e$-marked responses in Example (9). Ne-marked responses tend to appear in situations where the speaker has trouble recalling his/her experience. $N e$ presents what has just entered the speaker's awareness. In this sense, it is the same as a ne-marked response to an immediate situation (see 4.1), which presents the speaker's new awareness. On the other hand, a yone-marked response does not associate with a speaker's recollection difficulties. In other words, the speaker does not use yone to present what has just entered the speaker's awareness; instead, yone displays one's existing awareness.

As Example (9) shows, ne-marked responses tend to occur with the change-of-state maker " $a:$ :" (Heritage, 1984). In the data for this study, 43 responses marked with ne or yone occur with " $a: .$. " Eighty-six percent (37 cases) occur with " $a::$ " and $n e$, while only 14 percent ( 6 cases) are prefaced by " $a::$ " and yone. This data indicates that the speaker tends to use ne to present information as something that has just entered one's awareness at the discourse site, even in a situation involving recalling the speaker's experience. Although the experience per se is certainly not new, a speaker can present it as a piece of new information by using ne. In contrast, " $a::+$ yone" is deployed where the speaker does not experience any recall issues. The speaker uses yone to indicate previous experience or knowledge, rather than some newly-learned information that has just entered the speaker's awareness. 
Examples, such as Example (11), show how yone works with " $a: .$. " to indicate already-known information that just entered speaker E's awareness.

Speakers $\mathrm{L}$ and $\mathrm{E}$ are talking about people they met at a clinic where they worked as interns. $\mathrm{S}$ Sensei (Mr./Ms. S) is a person with whom both speakers L and E worked. When asked about his opinion of S Sensei by speaker L (line 1), speaker E comments that S Sensei is smart; yone and " $a:: "$ are attached.

(11)

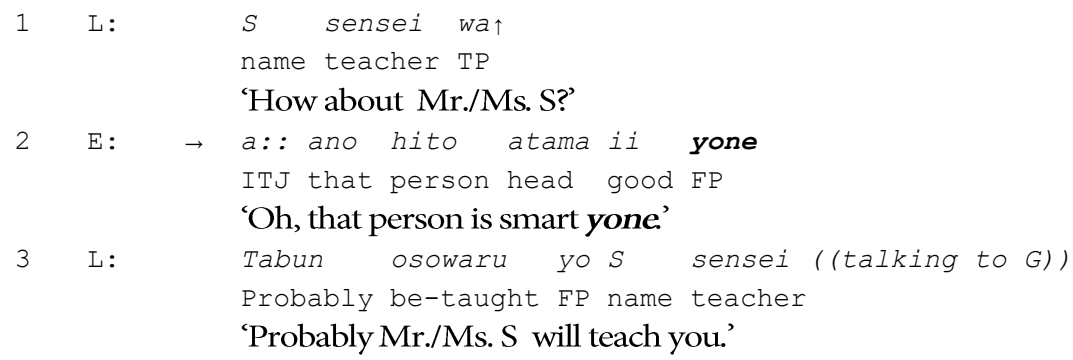

In Example (11), “a::” still functions as a marker of change-of-state, and speaker L's question in line1triggers the use of yone. However, unlike Example (9), speaker E does not have difficulty in recall.

In sum, these examples demonstrate that the use of yone or ne can be decided by how the speaker wants to present his/her awareness rather than by the information per se.

\subsection{Response to the Answer to a Question}

In this section, we examine the use of yone and ne in question responses. The targeted yone and ne are in the line 3 position, as shown in Table 1.

\begin{tabular}{|c|c|c|}
\hline \multicolumn{3}{|c|}{ Response to the answer to a question } \\
\hline 1 & & Question \\
\hline 2 & & Answer \\
\hline 3 & $\rightarrow$ & Response + yone/ne \\
\hline
\end{tabular}

Table 1. Response to the answer to a question

When used in response to a question's answer, the question, i.e., line 1, is designed differently, as shown in Table 2.

\begin{tabular}{ll|ll}
\hline \multicolumn{2}{c}{$N e$-marked response } & \multicolumn{2}{c}{ Yone-marked response } \\
\hline 1 & WH question or Polar question & 1 & negative question/WH question + candidate answer \\
2 & Answer & 2 & Answer \\
3 & $N e$-marked response & 3 & Yone-marked response \\
\hline
\end{tabular}

Table 2. Yone and ne in response to the answer to a question

For $n e$-marked responses, the questions are $\mathrm{WH}$ questions or polar questions. However, for yone-marked responses, questions are primarily negative questions or in the form of "WH question + candidate answer." In this study's data, 14 ne- or yone-marked utterances appear as a response to the answer to a question. Table 3 shows the distribution.

\begin{tabular}{lcccc}
\hline & WH question & Polar question & Negative questions & WH question + candidate answer \\
\hline Ne-marked response & 4 & 6 & 0 & 0 \\
Yone-marked response & 0 & 1 & 2 & 1 \\
Total & 4 & 7 & 2 & 1 \\
\hline
\end{tabular}

Table 3. The distribution of yone and $n e$ in response to the answer to a question 
To examine this point, observe the following examples:

(12)

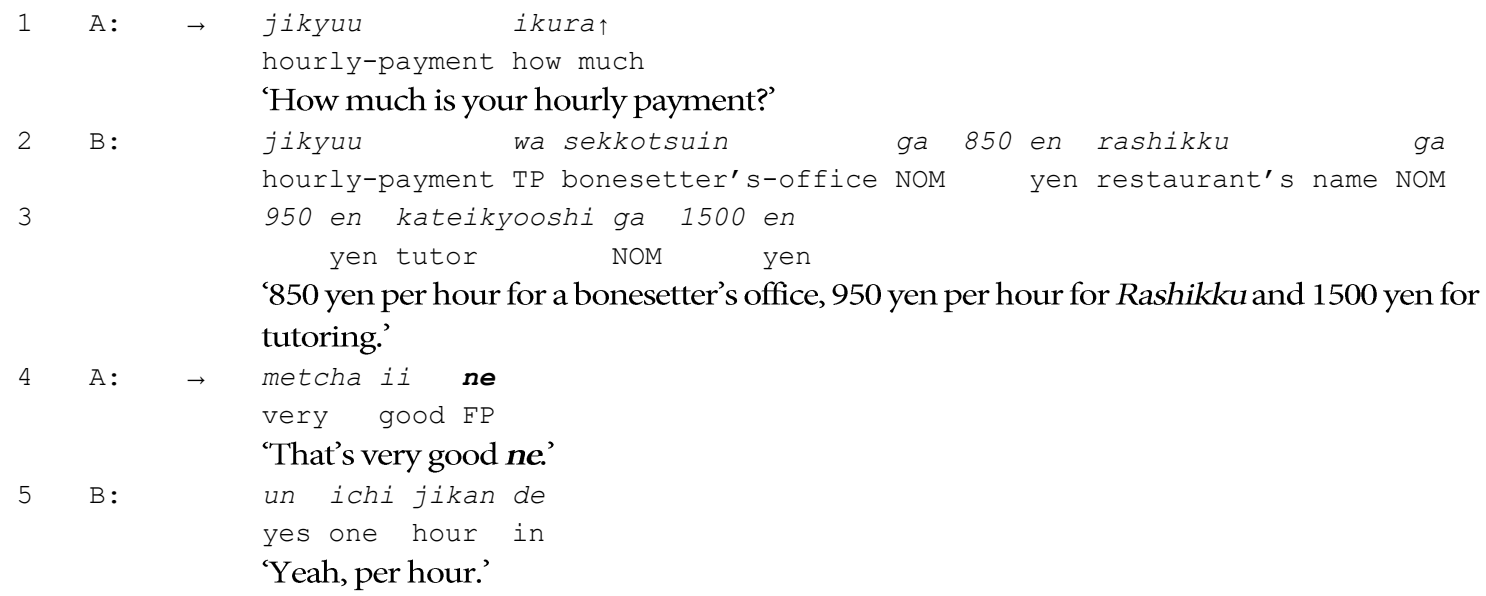

In Example (12), four participants talk about their part-time jobs. First, speaker A asks about speaker B's hourly payment by using a WH question: "How much is your hourly payment?" (line 1). The question indicates that speaker A does not possess any knowledge about speaker B's salary. The information she receives from speaker B's answer in lines 2 and 3 thus forms her response. Example (12) illustrates that a ne-marked assessment reflects a speaker's awareness established when receiving information.

Negative questions, or WH questions followed by candidate answers, present a speaker's existing awareness, as illustrated by yone-marked responses in Examples (13) and (14). For instance, in Example (13), four participants talk about the hourly pay for their part-time jobs. Before this segment, speaker G says that even though he wants more money, he tolerates his low hourly pay rate because the part-time job is comfortable and close to his home.

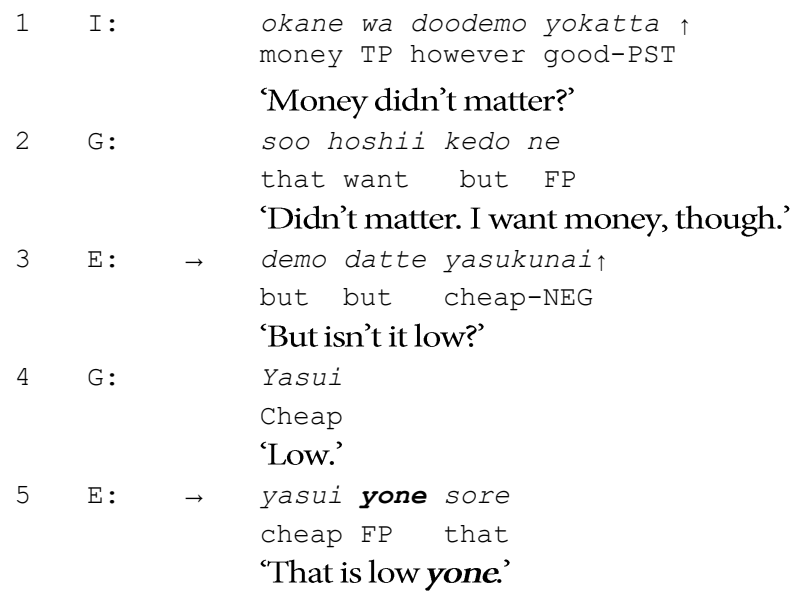

In line 3, speaker E's question is negative, i.e., "yasukunai (isn't it cheap?)." Also, "datte" is used to strengthen the speaker's assertion and make others change their stance (Mori, 1994). The combination of "datte" and negative question shows speaker E already thinks that speaker G's pay rate is low. The question design indicates the question's purpose is to solicit an affirmative answer, not merely a responsive answer from speaker G. Upon receiving speaker G's expected affirmative answer (line 4), speaker E produces a yone-marked utterance (line 5). 
In Example (14), yone appears in response to the answer to a question in the form of "WH question + candidate answer." Four participants are talking about their part-time jobs.

(14)

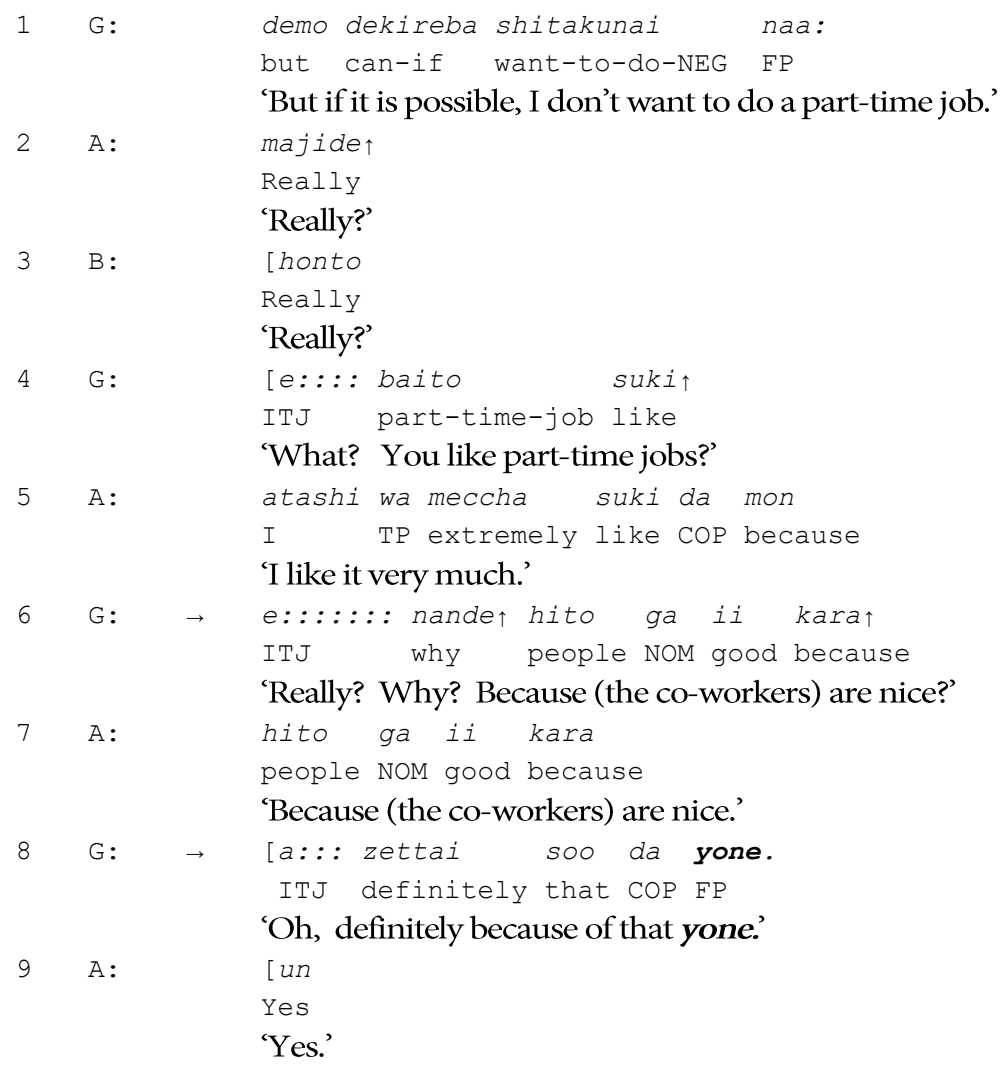

Speaker G says that she does not want a part-time job (line 1), while speaker A says that she likes her part-time job very much (line 5). Surprised by speaker A's opposite opinion, speaker G first asks the reason using a WH question, i.e., "nande (why)." Then she produces a candidate answer: because speaker A's co-workers are nice (line 6). It is notable that the candidate answer, which is in the form of a polar question, does not stand alone; the formation of "WH question + candidate answer" shows that speaker G already has an opinion. Confirmed by speaker A (line 7), speaker G produces the yone-marked utterance in line 8 . Here yone is chosen rather than $n e$ because of speaker A's opinion that "hito ga ii kara (because they are nice)" was previously expressed in the specially designed question formation in line 6 . She also upgrades her opinion with the adverb "zattai (definitely)" (line 8). This example clearly illustrates that yone presents the speaker's existing awareness.

Example (15) illustrates one case where yone can respond to the answer to a polar question. Four participants talk about another classmate who quit his part-time job. In line 1, speaker B asks whether the classmate is still coming to school. When speaker $\mathrm{G}$ tells her the classmate was not at school yesterday (line 4), speaker B produces in line 5 a response with yone and " $a:$. ."

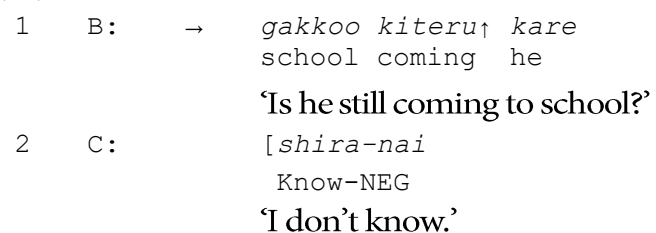




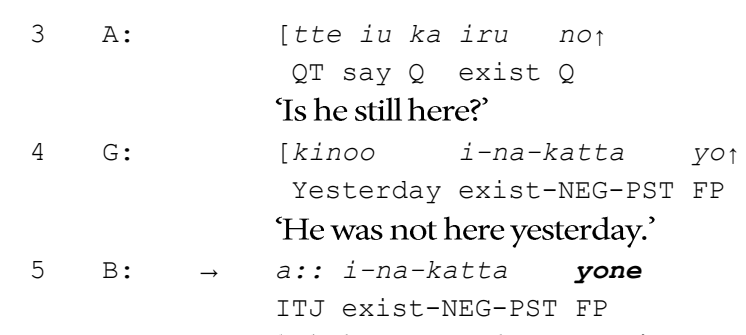

'Oh, he was not here yone.'

In Example (12), as mentioned previously, speaker A produced the $n e$-marked response to the answer of a WH question because he has no access to speaker B's salary. In contrast, in Example (15), speaker B probably knows whether the classmate was at school yesterday, given that they are classmates and possibly take the same classes. Like Example (11), yone is also used as the maker of change-of-state "a::." Here, yone, triggered by speaker G's answer in line 4, can also be considered already-known information that has just entered her awareness.

The preceding examples of yone and ne demonstrate the distinctions between yone and ne in response to a question's answer. Questions associated with a ne-marked response tend to be WH questions or polar questions, indicating the speaker seeks an answer because the speaker lacks knowledge or information. A ne-marked response also shows that the speaker's awareness manifests upon hearing an answer. In this sense, the response represents new awareness.

In contrast, a yone-marked response primarily occurs when answering negative questions or with "WH question + candidate answer" patterns. These question forms reveal that the speaker does not merely seek an answer but seeks an answer that confirms the awareness he/she has already established. Thus, using yone as a response to an answer presents the speaker's existing awareness.

\subsection{Response to Assessments}

In this section, using yone and ne in response to assessments is examined. The present study primarily focuses on ne- and yone-marked responses to assessments without ne or yone. The environment examined in the present study is shown in Table 4. Ne and yone in second assessment positions are considered.

\begin{tabular}{lll}
\hline \multicolumn{3}{l}{ Response to assessment } \\
\hline 1 & Assessment \\
2 & $\rightarrow$ & Assessment + yone/ne \\
\hline
\end{tabular}

Table 4. Yone and ne in response to assessments

First, ne-marked responses are examined. Four females talk about whether they prefer dogs or cats.

(16)

$\begin{array}{ll}\text { 1 B: } & \text { kekka inu ha ga ookatta tte yuu } \\ & \text { result dog group NOM many-past QT say } \\ & \text { 'The result was that more people prefer dogs.' } \\ & \text { inu ha da ne. } \\ & \text { dog group COP FP } \\ & \text { 'More people prefer dogs.' } \\ & \text { un tooron ni naranakatta ne } \\ & \text { ITJ discussion to became-NEG-PST FP } \\ & \text { 'well, it didn'tbecome a discussion.' } \\ & \text { atashi neko da yo: : toka ni naranakata } \\ & \text { I cat COP FP like to became-NEG } \\ & \text { 'Nobody said I prefer cats.' }\end{array}$




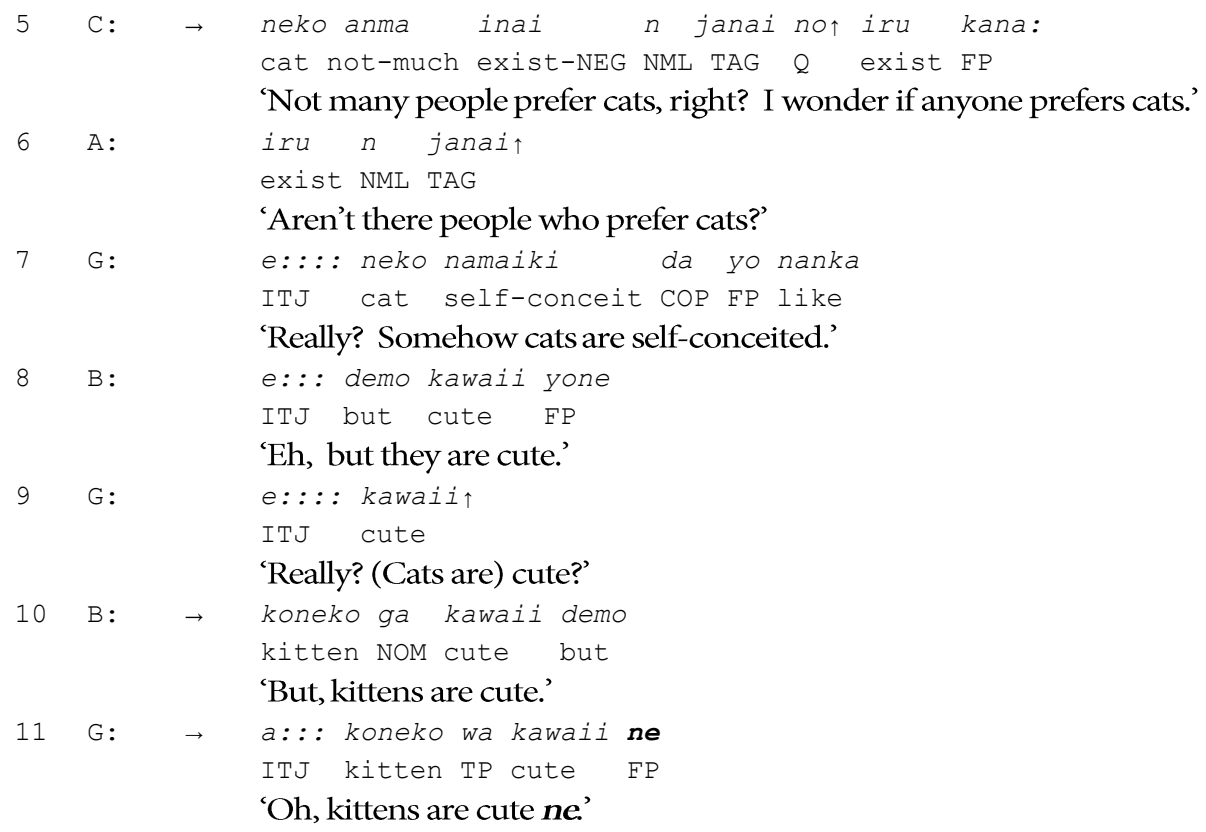

They conclude they prefer dogs to cats in line 1 . Speaker $\mathrm{G}$ is a dog person, and that might be why she is surprised in line 9 when speaker B mentions that cats are cute (line 8). Upon speaker G's reaction, speaker B modifies her statements by saying kittens are cute (line 10). In line 11, speaker G supports speaker B's view that kittens are cute by using ne. First, she contrasts kittens with adult cats by using the topic marker contrastive "wa," showing her opinion that kittens are cute but not adult cats (line 11). This opinion corresponds to her utterance in line 7, in which she explains why she does not like cats, i.e., she thinks cats are conceited.

Speaker G's utterance in line 11 is prefaced with a prolonged interjection " $a: \because$," which corresponds with "oh" in English and is a change-of-state marker (Heritage, 1984). Here, before speaker B's utterance in line 10 that kittens are cute, speaker G opines that cats are not cute. After hearing speaker B's statement in line 10, speaker G changes the referent of her assessment from "cats in general" to "kittens in particular." In this sense, ne presents speaker G's new awareness because she did not think that cats were cute until speaker B's line 10 assessment.

Example (17) demonstrates how a speaker can use yone to display one's existing awareness. Before this segment, four female participants talk about speaker A's part-time job. Speaker A works at a famous chocolate store.

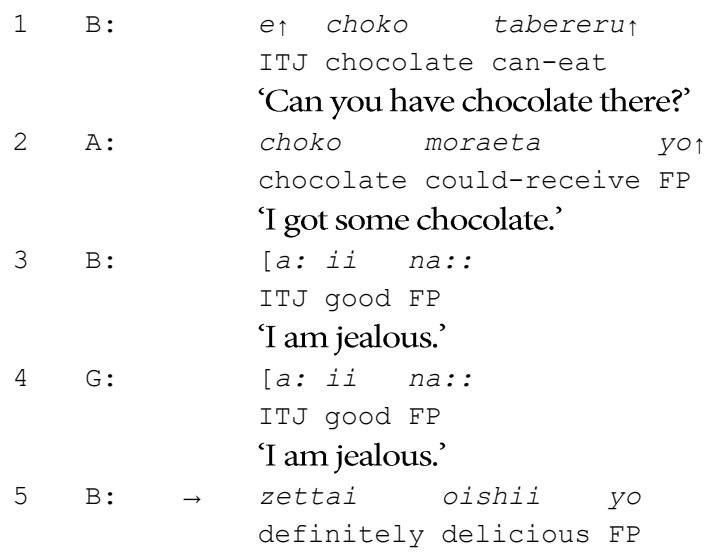




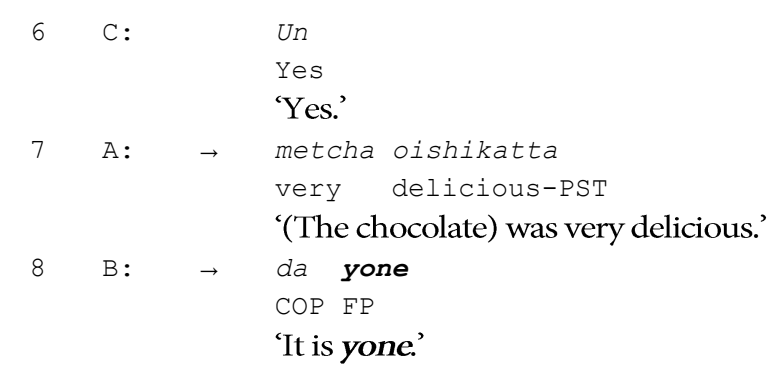

When speaker B finds out that speaker A receives some free chocolates, she immediately comments on the taste of the chocolates (line 5). In line 7, speaker A upgrades her comment on chocolate with the adverb "metcha (very)," saying it was very delicious. Speaker B's yone-marked response to speaker A's assessment (line 8) corresponds to her comment in line 5, i.e., "zettai oishii yo (definitely delicious)." Thus, Example (17) illustrates that yone displays a speaker's existing awareness.

\subsection{Discussion}

The data in this study shows that only ne is used to respond to immediate situations such as what a speaker has just seen, heard, or known. Prefacing ne with the change-of-state marker " $a:$ :" or " $j a$ " indicates previous discourse leading to the speaker's new awareness (Hamada, 1991; Heritage, 1984). Yone is not found in such a situation.

$\mathrm{Ne}$ can be used in recall. In the examples, although information is already known to the speaker, it is not in the speaker's awareness before the $n e$-marked utterance. Using $n e$ indicates that information just entered the speaker's awareness. In this sense, the function of $n e$ is consistent with the immediate situation; that is, the speaker uses ne to present already-known information as a new awareness. In contrast, because yone indicates a speaker's existing awareness, the change-of-state marker " $a::$ " does not frequently preface yone-marked responses.

Different question designs result in different uses of ne and yone in response to a question's answer. In the $n e$ examples, questions are $\mathrm{WH}$ questions or polar questions, indicating speakers seek specific information. Also, ne-marked responses, in this case, tend to occur with the changeof-state marker " $a: .$. " Thus, the use of ne reflects a speaker's new awareness. In the yone examples, the question design is different. Yes, speakers also seek the answer, but they already recognize possible answers when articulating the questions. One particular question design (negative question or question in the form of "WH question + candidate answer") solicits confirmation of the speaker's existing awareness rather than seeking new information. Thus, when an answer confirms knowledge, the speaker's response to it tends to be associated with the marker yone.

When $n e$ is used in second assessments to respond to first assessments, the $n e$-marked second assessment tends to be different from the assessment on the same referent that the speaker made in previous discourse. When using yone in such a situation, the yone-marked second assessment remains consistent with prior assessments made or implied by the speaker. In this sense, yone presents a speaker's existing awareness.

Now let us examine the use of yone and ne in Example (18), four participants are talking about their ideal partners. Before this segment, they talked about what kind of things they do not like.

$$
\begin{aligned}
& 1 \mathrm{H}: \quad \text { kechi toka } \\
& \text { stingy like } \\
& \text { 'Like being cheap?' } \\
& 2 \mathrm{~K}: \rightarrow \text { a: kechi [iya da ne } \\
& \text { ITJ stingy dislike COP FP } \\
& \text { 'Oh, I don't like being cheap ne.' }
\end{aligned}
$$




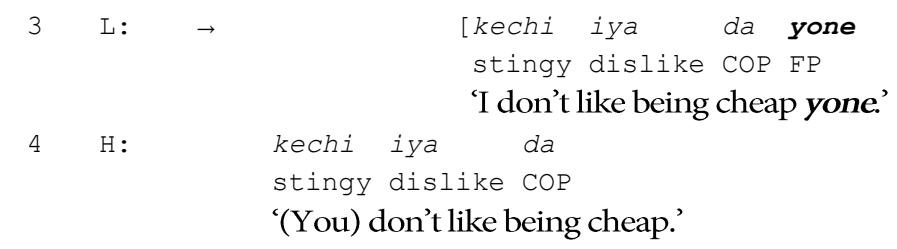

When speaker H brings up "being cheap," speakers K and L immediately respond to it with almost the same assessment. The difference is that speaker K's ne-marked response prefaces the change-of-state maker " $a::$ " while speaker L's yone-marked response does not. Using only conversational data, it is indeed impossible to know a speaker's underlying intention. However, a reasonable interpretation exists to explain the differences between yone and $n e$ in response: Speaker $\mathrm{K}$ uses $n e$ to present her new awareness; that is, she thinks at the moment of utterance that being cheap is not good. Speaker L uses yone to indicate her existing awareness; that is, she presents her thought in this way because she believed for a long time that being cheap is not good.

Example (18) is different in a noteworthy way from the four types of responses examined in this study. Speaker K and Speaker L use ne and yone to respond to a new topic. The new topic is not newly-learned information, nor does the response occur in a similar turn with other cases included in the study. It appears that the proposed hypothesis in this study is also able to explain the use of yone and ne in different situations, which are unexamined closely in the present study. Future research should explore this point with examples of yone and ne in other responding contexts. ${ }^{6}$

\section{Conclusion}

This study examined the differences between yone and $n e$ in the context of responses with naturally occurring conversation data. This study has found that generally, ne is used to present the speaker's new awareness while yone shows the speaker's existing awareness. Also, this study shows that using yone or $n e$ can be decided by how the speaker presents his/her state of awareness, rather than by the information per se to which yone or ne is attached.

This study is limited in several ways. First, the differences between yone and ne demonstrated in the present study apply within the context of four types of response. While the proposed hypothesis appears to successfully explain the difference between yone and ne in Example (18), the present study could not further explore this point due to the limited data. Future research regarding whether this hypothesis works in other settings, such as seeking confirmation or providing new information, both contexts in which the use of yone and ne overlap, may further expand the understanding of yone and ne. Second, this study focuses on using yone and ne to consider speakers' states of awareness and does not analyze the pragmatic functions of yone and $n e$ in response in detail. Further investigation into the difference of pragmatic functions of yone and $n e$ in response and other situations is strongly recommended.

Despite its limitations, this study certainly adds to our understanding of complex Japanese sentence-final particles. It also extends our knowledge of Akatsuka's (1985) proposal that Japanese grammar is sensitive to the cognitive distinction between "newly-learned information" and the

\footnotetext{
${ }^{6}$ In addition, as one reviewer points out, the order of " $n$ " and "yone" in Example (18) cannot be reversed. That is, it is unnatural to say "a kechi iya da yone" followed by "kechi iya da ne" in a situation in which two speakers are almost simultaneously responding to a question. While this irreversibility seems to be naturally accounted for by this study about the use of "yone" and "ne," this point cannot be elaborated due to limited data and should be subject to further exploration.
} 
"state of knowledge." The methods used for this study may be applied to other research on final sentence particles. Considering the complexity and frequent use of yone and $n e$ in conversation, the insights gained from this study may also be of assistance to the field of teaching Japanese as a foreign language.

\section{Transcription Conventions}

1. Transcript symbols

[ the point where overlapping talk begins

] the point where overlapping talk ends

(.) micro-pause

(0.0) length of silence

$:$ noticeably lengthened sound

$=\quad$ latched utterance

$\uparrow \quad$ rising intonation

(( )) transcriber's descriptions

hh laughter

2. Abbreviations

AUX auxiliary

COP copula

FP final particle

ITJ interjection

LK nominal linking particle

NEG negative morpheme

NML nominalizer

NOM subject marker

O object marker

PST past tense

Q question marker

QT quotative marker

TAG tag-like expression

TP topic marker

\section{References}

Noriko Akatsuka (1985). Conditionals and the epistemic scale. Language 61(3): 625-639.

Yuko Asano-Cavanagh (2011). An analysis of three Japanese tags: Ne, yone, and daroo. Pragmatics \& Cognition 19 (3):448-475.

Haruko Minegishi Cook (1990). The sentence-final particle $\mathrm{Ne}$ as a tool for cooperation in Japanese conversation. Japanese/Korean Linguistics1: 29-44.

Haruko Minegishi Cook (1992). Meanings of non-referential indexes: A case study of the Japanese sentence-final particle ne. Text-Interdisciplinary Journal for the Study of Discourse 12(4): 507-540.

Haruko Minegishi Cook (2001). Particles. In Alessandro Duranti (ed.), Key Terms in Language and Culture, 176-179. Malden, Blackwell Publishers. 
John Goldsmith and Erich Woisetschlaeger (1982). The logic of the English progressive. Linguistic Inquiry 13(1): 79-89.

Jeanette K Gundel (1985). Shared knowledge' and topicality. Journal of Pragmatics 9 (1): 83 107.

Mari Hamada (1991). Dewa' no kinoo: suiron to seitsuzokugo [The functions of 'dewa': inference and connectives]. Handai Nihongo Kenkyuu 3: 25-44. (in Japanese)

Yoko Hasegawa (2010). The sentence-final particles ne and yo in soliloquial Japanese. Pragmatics 20 (1):71-89.

Atsuko Hasunuma (1992). Shuujoshi no fukugookei 'yone' no yoohoo to kinoo [The use and functions of the compound sentence-final particle 'yone']. Taishoo Kenkyuи Dainigoo: Hatsuwa Maakaa Nitsuite: 63-77. (in Japanese)

Atsuko Hasunuma (1995). Taiwa niokeru kakunin kooi 'daroo' 'janaika' 'yone' no kakunin yoohoo [Confirmation of action in dialogue: On the confirmation function of 'daroo' 'janaika' 'yone']. In Niida Yoshio (ed.) Fukubun no Kenkyuu [Studies of Complex Sentences], 389419. Tokyo, Kuroshio Shuppan. (in Japanese)

Kaoru Hayano (2011). Claiming epistemic primacy: yo-marked assessments in Japanese. In Tanya Stivers, Lorenza Mondada, and Jakob Steensig (ed.), The Morality of Knowledge in Conversation, 58-81. Cambridge, Cambridge University Press.

Kaoru Hayano (2013). Territories of Knowledge in Japanese Conversation. Utrecht, LOT.

John Heritage (1984). A change-of-state token and aspects of its sequential placement." In John Heritage and J. Maxwell Atkinson (ed.) Structures of Social Action: Studies in Conversation Analysis, 299-345. Cambridge, Cambridge University Press.

John Heritage (2002). Oh-prefaced responses to assessments: a method of modifying agreement/disagreement. In C. Ford, B. Fox, and S. A. Thompson (ed.), The language of turn and sequence, 196-224. Oxford, Oxford University Press.

John Heritage and Geoffrey Raymond (2005). The terms of agreement: indexing epistemic authority and subordination in talk-in-interaction. Social Psychology Quarterly 68 (1):15-38.

Eiko Izuhara (1993). 'Ne' to 'yo' saikoo - 'ne' to 'yo' no komyunikeeshon kinoo no koosatsu kara [Revisit ' $n e$ ' and ' $y o$ '- an analysis of the communicative functions of ' $n e$ ' and ' $y o$ ']. Nihongo Kyooiku:103-114. (in Japanese)

Eiko Izuhara (1994). Kandooshi kantoojoshi shuujoshi 'ne/nee' no intoneeshonn - danwa shinkoo tono kakawari kara [The intonation of interjection, interjectory particle, sentence-final particle 'ne/nee'- the relation with conversation development]. Nihongo kyooiku: 96-107. (in Japanese)

Eiko Izuhara (2001). 'Ne' to 'yo' saisaikoo [Re-revisit 'ne' and 'yo']. Aichi Gakuin Daigaku Kyooyoobu Kiyoo 49(1):35-49. (in Japanese)

Eiko Izuhara (2003). Shuujoshi 'yo' 'yone' 'ne' saikoo [Revisit sentence-final particle 'yo' 'yone' 'ne']. Aichi Gakuin Daigaku Kyooyoobu Kiyoo 51(2): 1-15. (in Japanese)

Eiko Izuhara (2008). Kantoojoshi shuujoshi no danwa kanri kinoo bunseki - 'ne' 'yone' 'yo' no baai [A discourse management functional analysis of interjectory and sentence-final particle 'ne' 'yone' 'yo']. Aichi Gakuin Daigaku Kyooyoobu Kiyoo 56(1): 67-82. (in Japanese)

Gail Jefferson (1984). Transcript notation.” In J. Heritage and J. Maxwell Atkinson (ed.) Structures of Social Action: Studies in Conversation Analysis, ix-xvi. Cambridge, Cambridge University Press.

Akio Kamio (1994). The theory of territory of information: the case of Japanese. Journal of Pragmatics 21 (1): 67-100.

Akio Kamio (1995). Territory of information in English and Japanese and psychological utterances. Journal of Pragmatics 24 (3): 235-64. 
Akio Kamio (1997). Territory of Information. Amsterdam, John Benjamins Publishing.

Yasuhiro Katagiri. (2007). Dialogue functions of Japanese sentence-final particles ' $y o$ ' and ' $n e$.' Journal of Pragmatics 39 (7): 1313-23.

Shigehiro Kato (2001). Bunmatsu joshi 'ne' 'yo' no danwa koosei kinoo [The discourse constructive functions of the sentence-final particles ' $n e$ ' and 'yo']. Toyama Daigaku Jinbun Gakubu Kiyoo 35:31-48. (in Japanese)

Susumu Kuno (1972). Functional sentence perspective: A case study from Japanese and English. Linguistic Inquiry 3: 269-320.

DuckYoung Lee (2007). Involvement and the Japanese interactive particles ne and yo. Journal of Pragmatics 39 (2):363-88.

Senko Maynard (1993). Discourse Modality: Subjectivity, Emotion, and Voice in the Japanese Language. Amsterdam, John Benjamins Publishing.

Naomi H McGloin, Mustuko Endo Hudson, Fumiko Nazikian, and Tomomi Kakegawa (2013). Modern Japanese Grammar: A Practical Guide. London, Routledge.

Kazuhito Miyazaki (2002). Sheloshim ' $n e$ ' to ' $n a$ ' [The sentence-final particles ' $n e$ ' and ' $n a$ ']. Handai Nihongo Kenkyuu14. 1-19. (in Japanese)

Junko Mori (1994). Functions of the connective datte in Japanese conversation. Japanese/Korean Linguistics 4:147-163.

Emi Morita (2002). Stance marking in the collaborative completion of sentences: final particles as epistemic markers in Japanese. Japanese/Korean Linguistics 10: 220-233.

Keiko Noda (1993). Shuujoshi 'ne' to 'yo' no kinou: 'yone' to kasanaru baai [the functions of sentence-final particles ' $n e$ ' and ' $y o$ ': the cases of overlapping 'yone']. Gengo Bunka to Nihongo Kyooiku 6:10-21. (in Japanese)

Ellen F Prince (1992). The ZPG letter: subjects, definiteness, and information-status." In W. C. Mann and S. A. Thompson (ed.), Discourse Description: Diverse Linguistic Analyses of a Fund-raising Text, 295-325., Amsterdam, John Benjamins Publishing.

Anita Pomerantz (1984). Agreeing and disagreeing with assessments: some features of preferred/dispreferred turn shaped." In J. Heritage and J. Maxwell Atkinson (ed.), Structures of Social Action: Studies in Conversation Analysis, 57-101. Cambridge, Cambridge University Press.

Hideki Saigo (2011). The Japanese Sentence-final Particles in Talk-in-interaction. Amsterdam, John Benjamins Publishing.

Emanuel A Schegloff (2007). Sequence Organization in Interaction: A Primer in Conversation Analysis I. Cambridge, Cambridge University Press.

Dan Slobin and Ayhan Aksu (1982). Tense, aspect and modality in the use of the Turkish evidential. In P. J. Hopper (ed.), Tense-aspect: Between Semantics and Pragmatics: 185-200. Amsterdam, John Benjamins Publishing.

Yukinori Takubo and Satoshi Kinsui (1997). Discourse management in terms of mental spaces. Journal of Pragmatics 28 (6): 741-58.

Hiroko Tanaka (2000). The particle $n e$ as a turn-management device in Japanese conversation. Journal of Pragmatics 32 (8):1135-76.

Jun Xu (2016). An Analysis of the Japanese Sentence-Final Particle Yone. Ph.D. thesis, University of Wisconsin Madison, Madison, Wisconsin.

Huifang Zhang (2009). Shizen kaiwa niokeru 'yone' no imi ruikei to hyoogen kinoo [The types of meaning and functions of 'yone' in natural conversation]. Gengogaku Ronsoo Onrain Ban 2: 17-32. (in Japanese) 